\title{
The Influence of Patient Race and Activation on Pain Management in Advanced Lung Cancer: a Randomized Field Experiment
}

\author{
Cleveland G. Shields, $P h D^{1,2,3}$, Jennifer J. Griggs, $M D, M P H^{4,5}$, Kevin Fiscella, $M D, M P H^{6,7,8}$, \\ Cezanne M. Elias, $P h D^{3}$, Sharon L. Christ, $P h D^{3,9}$, Joseph Colbert, BA ${ }^{10}$, Stephen G. Henry, MD, MSc ${ }^{11}$, \\ Beth G. Hoh, MSW' ${ }^{12}$, Haslyn E. R. Hunte, PhD ${ }^{13}$, Mary Marshall, MS ${ }^{3}$, Supriya Gupta Mohile, MD, MS ${ }^{14}$, \\ Sandy Plumb, BS $6,7,14$, Mohamedtaki A. Tejani, MD, MS ${ }^{14}$, Alison Venuti, BS ${ }^{6}$, and Ronald M. Epstein, \\ $M D^{6,7,12,14,15,16}$
}

\begin{abstract}
${ }^{1}$ Center for Cancer Research, Purdue University, West Lafayette, IN, USA; ${ }^{2}$ Regenstrief Center for Healthcare Engineering, Purdue University, West Lafayette, IN, USA; ${ }^{3}$ Human Development \& Family Studies, Purdue University, West Lafayette, IN, USA; ${ }^{4}$ Department of Internal Medicine, Hematology/ Oncology Division, and Health Management and Policy, University of Michigan School of Medicine, Ann Arbor, MI, USA; ${ }^{5}$ Department of Health Management \& Policy, University of Michigan School of Medicine, Ann Arbor, MI, USA; ${ }^{6}$ Center for Communication and Disparities Research, University of Rochester School of Medicine, Rochester, NY, USA; ${ }^{7}$ Department of Family Medicine, University of Rochester School of Medicine, Rochester, NY, USA; ${ }^{8}$ Department of Public Health Sciences, University of Rochester School of Medicine, Rochester, NY, USA; ${ }^{9}$ Department of Statistics, Purdue University, West Lafayette, IN, USA; ${ }^{10}$ Department of Biostatistics, University of Michigan School of Medicine, Ann Arbor, MI, USA; " 'Department of Internal Medicine, University of California Davis School of Medicine, Sacramento, CA, USA; ${ }^{2}$ Department of Psychiatry, University of Rochester School of Medicine, Rochester, NY, USA; ${ }^{13}$ School of Public Health, Department of Social and Behavioral Sciences, West Virginia University, Morgantown, WV, USA; ${ }^{14}$ James P Wilmot Cancer Center, University of Rochester School of Medicine, Rochester, NY, USA; ${ }^{15}$ Department of Medicine, University of Rochester School of Medicine, Rochester, NY, USA; ${ }^{16}$ Family Medicine Research Programs, University of Rochester, Rochester, NY, USA.
\end{abstract}

BACKGROUND: Pain management racial disparities exist, yet it is unclear whether disparities exist in pain management in advanced cancer.

OBJECTIVE: To examine the effect of race on physicians' pain assessment and treatment in advanced lung cancer and the moderating effect of patient activation.

DESIGN: Randomized field experiment. Physicians consented to see two unannounced standardized patients (SPs) over 18 months. SPs portrayed 4 identical roles-a 62-year-old man with advanced lung cancer and uncontrolled pain-differing by race (black or white) and role (activated or typical). Activated SPs asked questions, interrupted when necessary, made requests, and expressed opinions.

PARTICIPANTS: Ninety-six primary care physicians (PCPs) and oncologists from small cities, and suburban and rural areas of New York, Indiana, and Michigan. Physicians' mean age was 52 years $(\mathrm{SD}=27.17), 59 \%$ male, and $64 \%$ white.

MAIN MEASURES: Opioids prescribed (or not), total daily opioid doses (in oral morphine equivalents), guidelineconcordant pain management, and pain assessment.

KEY RESULTS: SPs completed 181 covertly audiorecorded visits that had complete data for the model covariates. Physicians detected SPs in 15\% of visits. Physicians prescribed opioids in $71 \%$ of visits; $38 \%$ received guideline-concordant doses. Neither race nor activation was associated with total opioid dose or guidelineconcordant pain management, and there were no interaction effects $(p>0.05)$. Activation, but not race, was associated with improved pain assessment ( $(\square, 0.46,95 \% \mathrm{CI}$

Received March 12, 2018

Revised August 30, 2018

Accepted November 19, 2018

Published online January 10, 2019
$0.18,0.74)$. In post hoc analyses, oncologists (but not PCPs) were less likely to prescribe opioids to black SPs (OR 0.24, 95\% CI 0.07, 0.81).

CONCLUSIONS: Neither race nor activation was associated with opioid prescribing; activation was associated with better pain assessment. In post hoc analyses, oncologists were less likely to prescribe opioids to black male SPs than white male SPs; PCPs had no racial disparities. In general, physicians may be under-prescribing opioids for cancer pain.

\section{TRIAL REGISTRATION: NCT01501006}

KEY WORDS: communication; lung cancer; doctor-patient relations; pain management; racial disparities.

J Gen Intern Med 34(3):435-42

DOI: $10.1007 / \mathrm{s} 11606-018-4785-Z$

(C) Society of General Internal Medicine 2019

\section{BACKGROUND}

Despite national attention to racial disparities in the assessment and treatment of cancer-related pain, ${ }^{1,2}$ black patients still report greater pain, ${ }^{3,4}$ potentially due to undertreatment. ${ }^{5,}$ ${ }^{6}$ Observational research documents that black patients are more likely to have underdiagnosed pain ${ }^{7,8}$ and are less likely to receive adequate pain medication. ${ }^{7,9,}{ }^{10}$ However, this research has been done primarily in early-stage cancer.

Physician-patient communication may contribute to disparities in cancer pain treatment. Compared to white patients with lung cancer, black patients talk less, ask fewer questions, make fewer requests for pain medications, and are more passive in 
decision-making; ${ }^{11}$ in turn, physicians provide less diseaserelated information.

Based on studies of communication in cancer and noncancer settings, we hypothesized that patient activation might improve pain assessment and thus modify the effect of race on prescribing. Activated patients ask questions, interrupt when necessary, make requests, and express opinions. ${ }^{11}$ Activation appears to engage physicians in deeper conversations, ${ }^{12}, 13$ and when patients are taught to be active, they are more satisfied with communication. ${ }^{14}$ Generally, black patients are less activated than white patients. ${ }^{15}$

Prior research on disparities in cancer pain management used mainly observational designs. ${ }^{7,}$, 10 The Social and Behavioral Influences Study overcomes these limitations by using a randomized field experiment to control patient presentation. We trained standardized patients (SPs) to identical roles that differed only by patient race and activation. First, we hypothesized that black SPs would be less likely to receive opioids, they would get lower doses of opioids, and fewer would receive guideline-concordant pain management compared to white SPs. Second, we hypothesized that physicians would engage blacks in less pain-related assessment. Finally, we hypothesized that activation would mitigate these disparities.

\section{METHODS}

\section{Overview}

We conducted a randomized field experiment in small metropolitan and rural areas of Indiana, Michigan, and New York. A detailed study protocol is available. ${ }^{16}$ Study sites received local institutional IRB approval. By design, we collected data at sites \#1 and \#2 between July 2012 and October 2014 and from site \#3 from March 2014 to November 2016. We trained black and white men to portray a 62-year-old with stage IV lung cancer with bone metastases and uncontrolled pain. We constructed four roles that differed by race and activation; otherwise, roles were identical. We deployed two same-race SPs to each participating physician. SP assignment to physicians was stratified by specialty. To reduce SP detection risk, we scheduled visit \#1 and visit \#2 at least 4 months apart. Office visits were covertly audio-recorded, transcribed, and analyzed for content and process. Physicians completed questionnaires at baseline asking about demographics, as well as attitudinal scales used for secondary analyses not reported here. We collected prescriptions, reviewed medical records, and analyzed audio-recordings to confirm prescribing data.

\section{Physician Subjects}

Study investigators approached oncologists and primary care physicians (PCPs) individually and at meetings after obtaining approval from their practice medical directors. Oncologists were eligible if they were not planning to leave their practice within 12 months and if they treated patients with solid tumors, including lung cancer. Participating physicians provided an office contact who helped to avoid difficulties with insurance issues, identity checks, and data entry in electronic health records. In our consent form, we told physicians that the purpose of the study was "to improve patient-physician communication and clinical decisions by examining social and personal characteristics that can affect clinical care and outcomes. More specifically, the study examines overall variations in communication patterns based on patient characteristics such as behavior, ethnicity, race, sex, literacy, socioeconomic status, and education."

\section{Standardized Patients}

SPs portrayed a divorced male who completed 1.5 years of college and worked as a carpenter/contractor before taking a job at a home improvement store 5 years ago. ${ }^{16}$ The SPs presented with a several-month history of stage IV lung cancer with painful bone metastases treated with radiation therapy and opioids. Before the visit, we mailed a realistic medical record detailing the medical history, medications, and contact information. The SPs were seeking care from a physician, having recently moved from another state to live closer to an adult child. They spontaneously reported having been prescribed hydrocodone/acetaminophen $10 \mathrm{mg}$ every $4 \mathrm{~h}$ as needed (60 oral morphine equivalents per day) but that they were taking at least $70 \mathrm{mg}$ daily because the medication "doesn't seem to be working as it used to." They described worsening dull chest and back pain, worse with deep inspiration, $7 / 10$ in general, improving to $5 / 10$ for $2 \mathrm{~h}$ after taking medication. They said they only had "a few" remaining pills, which "might be enough for a week."

Using criteria derived from Street et al., ${ }^{11}$ Hibbard et al., ${ }^{12}$, ${ }^{17}$ and Kaplan et al., ${ }^{18}$ we trained activated SPs to ask direct questions, to request information, to ask for clarification, and to redirect when their concerns were not addressed. They brought a list of questions and interrupted the physician at least once to ask for clarification. In contrast, we trained typical SPs to ask questions about following through with treatment, to express relatively few concerns, to appear satisfied with the information offered, and to say that they understood even when physician explanations were lacking.

We trained activated and typical SPs separately at each site. SPs were blinded to study hypotheses. Although SPs may have observed they were of different races, they were not informed that race was a primary factor examined in the study. The same SPs visited PCPs and oncologists. The lead SP trainer (AV) supervised SP recruitment, training, and monitoring at all sites. Each site had its own trainer who reviewed audio-recordings with the SPs to assess role fidelity and provide feedback. Trainers listened to audio-recordings within two business days of each visit for the first 15 visits, after every third visit thereafter, and more frequently if needed. The standardized role fidelity scale included items that distinguished between activated 
and typical roles; fidelity met our criterion of $90 \%$ or higher.

\section{Randomization and Blinding}

The study statistician (SLC) randomized physicians to see two black or two white SPs stratified by specialty (PCP vs. oncology). The statistician also randomized the order physicians would see activated and typical SPs, prepared a 1:1 randomization list, and put assignments in opaque envelopes, which research assistants used to assign SPs to consented physicians.

\section{Data Collection and Outcome Measures}

Immediately following the visit, the study coordinator at each site debriefed SPs about fidelity, logistics, and any difficulties encountered. Paper prescriptions were voided; electronic prescriptions and scheduled laboratory tests, imaging, referrals, and follow-up appointments were canceled unbeknownst to participating physicians. Research assistants entered the prescription data into MS Excel, which was read into SAS 9.0 for calculation of daily oral morphine equivalents using equianalgesic tables. ${ }^{19} \mathrm{~A}$ few days later, study staff notified the office that the SP would not be returning using various alibis (e.g., the patient chose another physician). Approximately 2 months after the final SP visit, we asked physicians to complete a form asking whether they suspected that they saw an SP and asked for identifying data to confirm their suspicions. After receiving physicians' responses, we asked office staff to send us a copy of the SP's medical record.

The recordings of the SP visits were professionally transcribed and research assistants coded the transcripts using the Measure of Physician Pain Assessment (MPPA), which captures physicians' responses to patients' expressions of concerns about pain. This measure was previously developed, piloted, and validated by our research team for use in outpatient cancer consultations ${ }^{20}$ to capture patient-centered exploration of topics such as the onset, location, and quality of pain.

We assessed (a) whether an opioid was prescribed, (b) if prescribed, at what total daily dose (expressed as oral morphine equivalents, including PRN dosing at allowed daily dose), and (c) whether the dose was adequate according to current guidelines. We relied on guidelines from the American Association of Hospice and Palliative Medicine, which suggest increasing opioid medications by at least $30 \%$ over the current dose for uncontrolled cancer pain. ${ }^{21}$ In this case, "adequate" was defined as at least $90 \mathrm{mg}$ oral morphine equivalents over $24 \mathrm{~h}$.

\section{Data Management and Statistical Analyses}

Research assistants double-entered survey and other data into MS Excel or Qualtrix ${ }^{\mathrm{TM}}$ files, which we imported into SAS 9.0. We used SAS for data management, variable creation, and dosage calculations, and the statistician analyzed data using STATA 14. We converted all opioid data into oral morphine doses and classified the medication into short-acting or longacting (e.g., sustained-release morphine, oral methadone, or fentanyl patch).

We used mixed effects linear regression to estimate the effects of SP race and activation on pain assessment and medication dosage. Similarly, we used mixed effects logistic regression used to model whether the dosage met clinical practice guidelines. Analyses accounted for the nesting of two visits within each physician. ${ }^{22}$ We tested for interactions between SP race and activation. Model control variables included physician specialty (oncologist or PCP), physician race, sex, age, and research site. Bootstrapped standard errors were used for opioid dose to correct for the non-normal distribution.

\section{Role of the Funding Source}

The National Cancer Institute of the National Institutes of Health funded this study. The funder had no role in the study's design, conduct, or reporting.

\section{RESULTS}

Fourteen SPs completed 181 visits with 96 physicians; 85 physicians completed 2 visits while 11 only completed one visit. Physicians were predominantly middle-aged (mean = $52.1, \mathrm{SD}=12.6)$, white $(64 \%)$, and male $(59 \%) ; 47 \%$ were oncologists, and 53\% were PCPs (26 family medicine, 25 general internal medicine). Fifteen percent of SP visits were detected by PCPs and by oncologists; the survey response rate was $97 \%$ (Fig. 1). SPs averaged 13 visits each with a range of $3-27$; one site was able to enroll only 6 physicians. Physician age and race were approximately equal across the eight cells of the model. Sex was approximately equal for PCPs, but only $32 \%$ of oncologists were female, reflecting the percentage of female oncologists in the population. ${ }^{23}$

Opioid Prescribing. In $71 \%$ of visits, physicians prescribed an opioid; prescribing did not differ by specialty ( $74 \%$ for oncologists and $68 \%$ for PCPs, $p>0.05$ ). The mean dose prescribed was $70.5 \mathrm{mg}$ oral morphine equivalents per day (range 0 to $300 \mathrm{mg}$ ). Using our prespecified criteria (at least $90 \mathrm{mg}$ daily oral morphine equivalent), in only $38 \%$ of visits was the dose adequate. Using mixed models, we found no statistically significant racial differences in whether a patient received an opioid prescription (Table 1). There was no statistically significant interaction effect of patient activation with patient race.

Opioid Doses. In mixed models that controlled for physician characteristics, clustering of SPs within physician, and site, we observed no racial difference in the dose of opioids prescribed (Table 2), and there was no interaction effect of patient activation with patient race. 


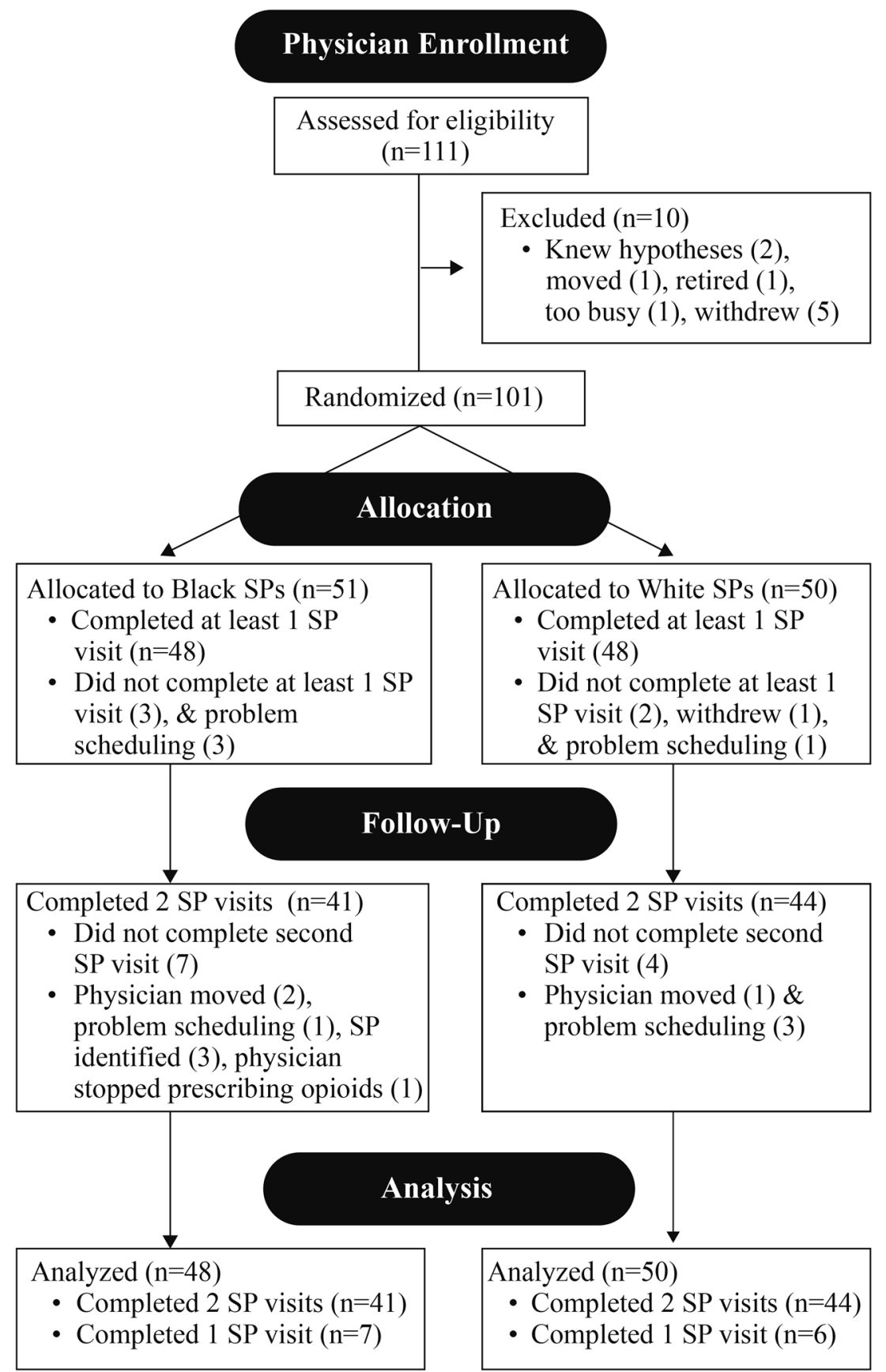

Fig. 1 CONSORT flow diagram.

Adequacy of Opioid Prescribing. Using our prespecified criteria of $\geq 90 \mathrm{mg}$ oral morphine equivalents daily as an adequate dose, we found no effect of race in prescribing an adequate dose, nor was there any interaction with patient activation (Table 3). Sensitivity analyses showed similar results when different dosage cut points were used.

Pain Assessment. The mean of the total scale was 24.78 (SD, 6.88 , range 3-36) and was reliably coded ( $\mathrm{ICC}=.72)$. The scale was subsequently standardized for model analysis. The activated role had an independent positive effect $(\beta, 0.43$, $95 \%$ CI $0.24,0.63$ ) on pain assessment (Table 4$)$. We found no effects of race and no interaction between race and role (activated vs typical).

Physician Specialty. Because PCPs might refer the patient to an oncologist with the expectation that the oncologist would prescribe opioids, and because we learned during the study that a few PCPs may have stopped prescribing opioids altogether, we performed secondary analyses to assess opioid prescribing by physician specialty. Oncologists were significantly less likely (OR $0.24,95 \%$ CI $0.07,0.81$ ) to prescribe opioids for black SPs compared to white SPs and were more likely to prescribe opioids to activated patients (OR 3.96, 95\% CI 1.24, 12.69) 
Table 1 Opioid Prescription vs. No Opioid Prescription by Standardized Patient Race, Activation, and Physician Characteristics (Mixed Model Logistic Regression)

\begin{tabular}{|c|c|c|c|c|c|c|}
\hline \multirow[b]{3}{*}{ Black SP } & \multicolumn{3}{|c|}{ Main effects } & \multicolumn{3}{|c|}{ Activation moderation } \\
\hline & \multirow{2}{*}{$\frac{\text { OR }}{0.47}$} & \multicolumn{2}{|c|}{$95 \% \mathrm{CI}$} & \multirow{2}{*}{$\frac{\mathbf{O R}}{0.40}$} & \multicolumn{2}{|c|}{$95 \% \mathrm{CI}$} \\
\hline & & 0.15 & 1.44 & & 0.10 & 1.61 \\
\hline Activated SP & 1.93 & 0.83 & 4.50 & 1.63 & 0.50 & 5.39 \\
\hline Interaction & & & & 1.38 & 0.26 & 7.26 \\
\hline Site & $0.22 *$ & 0.06 & 0.74 & $0.22 *$ & 0.06 & 0.74 \\
\hline $\begin{array}{l}\text { Physician } \\
\text { oncologist }\end{array}$ & 1.85 & 0.59 & 5.80 & 1.86 & 0.59 & 5.89 \\
\hline Physician female & 0.98 & 0.31 & 3.14 & 0.98 & 0.30 & 3.18 \\
\hline $\begin{array}{l}\text { Physician age } \\
\text { (years) }\end{array}$ & 0.99 & 0.94 & 1.03 & 0.99 & 0.94 & 1.03 \\
\hline Physician Black & 0.67 & 0.18 & 2.53 & 0.67 & 0.18 & 2.54 \\
\hline $\begin{array}{l}\text { Physician other } \\
\text { race }\end{array}$ & 0.74 & 0.15 & 3.62 & 0.74 & 0.15 & 3.66 \\
\hline \multirow[t]{2}{*}{ Fixed intercept } & 17.23 & 0.93 & 319.51 & 19.19 & 0.95 & 386.34 \\
\hline & $\sigma^{2}$ & \multicolumn{2}{|c|}{$95 \% \mathrm{CI}$} & $\sigma^{2}$ & \multicolumn{2}{|c|}{$95 \% \mathrm{CI}$} \\
\hline $\begin{array}{l}\text { Random } \\
\text { intercept }\end{array}$ & 1.62 & 0.85 & 3.10 & 1.64 & 0.86 & 3.15 \\
\hline
\end{tabular}

SP, standardized patient; $* p<0.05 ; \sim$ Referent $=$ white

compared to typical SPs (Table 5). No effect of race or activation was seen among PCPs. Physician race, sex, and age were not associated with prescribing patterns.

Site Effects. Across all analyses (Tables 1, 2, 3, 4, 5), the last data collection site ( site \#3) was consistently associated with lower prescribing.

There were no appreciable changes in the effect sizes for any of these analyses when we re-analyzed the data excluding detected visits.

\section{DISCUSSION}

We hypothesized that black SPs would receive less adequate treatment for pain in the context of advanced cancer and
Table 3 Guideline-Concordant Opioid Prescribing (Daily Oral

Morphine Equivalents Prescribed At Least a 30\% Increase) by Standardized Patient Race and Activation and Physician Characteristics (Mixed Model Logistic Regression Model)

\begin{tabular}{|c|c|c|c|c|c|c|}
\hline \multirow[b]{3}{*}{ Black SP } & \multicolumn{3}{|c|}{ Main effects } & \multicolumn{3}{|c|}{ Activation moderation } \\
\hline & \multirow{2}{*}{$\begin{array}{l}\text { OR } \\
1.78\end{array}$} & \multicolumn{2}{|c|}{$95 \% \mathrm{CI}$} & \multirow{2}{*}{$\frac{\text { OR }}{1.65}$} & \multicolumn{2}{|c|}{$95 \% \mathrm{CI}$} \\
\hline & & 0.88 & 3.59 & & 0.62 & 4.39 \\
\hline Activated SP & 1.09 & 0.56 & 2.12 & 1.02 & 0.39 & 2.64 \\
\hline Interaction & & & & 1.15 & 0.30 & 4.36 \\
\hline Site & $0.43^{*}$ & 0.21 & 0.88 & $0.43 *$ & 0.21 & 0.88 \\
\hline $\begin{array}{l}\text { Oncologist } \\
\text { (vs. PCP) }\end{array}$ & $3.10 * *$ & 1.44 & 6.66 & $3.10 * *$ & 1.44 & 6.67 \\
\hline $\begin{array}{l}\text { Female } \\
\text { physician }\end{array}$ & 0.60 & 0.28 & 1.27 & 0.60 & 0.28 & 1.27 \\
\hline $\begin{array}{l}\text { Physician age } \\
\text { (years) }\end{array}$ & 0.98 & 0.95 & 1.01 & 0.98 & 0.95 & 1.01 \\
\hline \multicolumn{7}{|l|}{ Physician race ${ }^{\sim}$} \\
\hline Black & 0.62 & 0.26 & 1.45 & 0.62 & 0.26 & 1.45 \\
\hline Asian & 0.33 & 0.11 & 1.01 & 0.33 & 0.11 & 1.01 \\
\hline \multirow{2}{*}{$\begin{array}{l}\text { Fixed } \\
\text { intercept }\end{array}$} & 1.99 & 0.32 & 12.55 & 2.07 & 0.32 & 13.52 \\
\hline & $\sigma^{2}$ & \multicolumn{2}{|c|}{$95 \% \mathrm{CI}$} & $\sigma^{2}$ & \multicolumn{2}{|c|}{$95 \% \mathrm{CI}$} \\
\hline $\begin{array}{l}\text { Random } \\
\text { intercept }\end{array}$ & 0.27 & 0.00 & 282.16 & 0.28 & 0.00 & 253.50 \\
\hline
\end{tabular}

SP, standardized patient; OR, odds ratio; CI, confidence interval $* p<0.05 ; * * p<0.01$

$\sim$ Referent $=$ white

uncontrolled pain. We did not observe an effect of race or activation on opioid prescribing; however, in post hoc analysis, we did find a difference in prescribing by race but only with oncologists, which we discuss later. Although activation improved pain assessment overall, activation did not modify the effect of race on opioid prescribing or on pain assessment, disconfirming our secondary hypotheses. Our results shed light on the conflicting findings regarding racial disparities in cancer pain management.

There are several explanations for the absence of hypothesized disparities. First, opioid prescribing for pain due to metastatic cancer may not be race-sensitive. ${ }^{24}$ Given broad

Table 2 Total Daily Oral Morphine Equivalent Dosing Prescribed by Standardized Patient Race and Activation and Physician Characteristics (Mixed Model Linear Regression)

\begin{tabular}{|c|c|c|c|c|c|c|}
\hline & \multicolumn{3}{|c|}{ Main effects } & \multicolumn{3}{|c|}{ Activation moderation } \\
\hline & B & $95 \% \mathrm{CI}$ & & ß & $95 \% \mathrm{CI}$ & \\
\hline Black SP & 10.93 & -10.23 & 32.09 & 10.63 & -20.78 & 42.04 \\
\hline Activated SP & -1.75 & -21.53 & 18.02 & -2.05 & -21.13 & 17.03 \\
\hline Interaction & & & & 0.59 & -36.72 & 37.91 \\
\hline Site & $-31.30 * *$ & -51.82 & -10.78 & $-31.29 * *$ & -51.99 & -10.58 \\
\hline Oncologist (vs. PCP) & $40.53 * * *$ & 20.78 & 60.27 & $40.53 * * *$ & 19.55 & 61.52 \\
\hline Female physician & -13.64 & -34.01 & 6.72 & -13.64 & -33.68 & 6.39 \\
\hline Physician age (years) & -0.10 & -0.94 & 0.74 & -0.10 & -0.92 & 0.72 \\
\hline \multicolumn{7}{|l|}{ Physician race } \\
\hline Black & -9.57 & -36.54 & 17.40 & -9.58 & -36.54 & 17.39 \\
\hline Asian & -19.98 & -46.46 & 6.50 & -19.99 & -46.27 & 6.30 \\
\hline \multirow[t]{2}{*}{ Fixed intercept } & $78.69 * *$ & 27.47 & 129.91 & $78.84 * *$ & 28.62 & 129.06 \\
\hline & $\sigma^{2}$ & $95 \% \mathrm{CI}$ & & $\sigma^{2}$ & $95 \% \mathrm{CI}$ & \\
\hline Random intercept & 18.47 & 4.57 & 74.60 & 18.48 & 4.54 & 75.19 \\
\hline
\end{tabular}

SP, standardized patient; $C I$, confidence interval; $P C P$, primary care physician

$* * p<0.01 ; * * * p<0.001$

$\sim$ Referent $=$ white 
Table 4 Patient-Physician Communication about Pain by Standardized Patient Race, Activation and Physician Characteristics (Mixed Model Linear Regression)

\begin{tabular}{|c|c|c|c|c|c|c|}
\hline \multirow[b]{3}{*}{ Black SP } & \multicolumn{3}{|c|}{ Main effects } & \multicolumn{3}{|c|}{ Activation moderation } \\
\hline & \multirow{2}{*}{$\frac{\boldsymbol{B}}{-0.04}$} & \multicolumn{2}{|l|}{$95 \% \mathrm{CI}$} & \multirow{2}{*}{$\frac{\boldsymbol{B}}{-0.01}$} & \multicolumn{2}{|l|}{$95 \% \mathrm{CI}$} \\
\hline & & -0.34 & 0.26 & & -0.37 & 0.35 \\
\hline Activated SP & $0.43 * * *$ & 0.24 & 0.63 & $0.46^{* *}$ & 0.18 & 0.74 \\
\hline Interaction & & & & -0.06 & -0.45 & 0.34 \\
\hline Site & $-0.81 * * *$ & -1.11 & -0.51 & $-0.81 * * *$ & -1.11 & -0.51 \\
\hline Oncologist (vs. PCP) & 0.24 & -0.07 & 0.55 & 0.24 & -0.07 & 0.55 \\
\hline Female physician & 0.31 & -0.01 & 0.63 & 0.31 & -0.01 & 0.63 \\
\hline Physician age (years) & -0.01 & -0.02 & 0.00 & -0.01 & -0.02 & 0.00 \\
\hline \multicolumn{7}{|l|}{ Physician race } \\
\hline Black & -0.16 & -0.52 & 0.21 & -0.16 & -0.52 & 0.21 \\
\hline Asian & -0.37 & -0.82 & 0.08 & -0.37 & -0.82 & 0.08 \\
\hline \multirow[t]{2}{*}{ Fixed Intercept } & 0.60 & -0.17 & 1.38 & 0.59 & -0.19 & 1.37 \\
\hline & $\sigma^{2}$ & $95 \% \mathrm{CI}$ & & $\sigma^{2}$ & $95 \% \mathrm{CI}$ & \\
\hline Random Intercept & 0.54 & 0.41 & 0.72 & 0.54 & 0.41 & 0.72 \\
\hline
\end{tabular}

$S P$, standardized patient; $C I$, confidence interval

$* p<0.05 ; * * p<0.01 ; * * * p<0.001$

$\sim$ Referent $=$ white

consensus among PCPs and oncologists regarding opioids for pain in this context, there may be less reluctance to provide opioids compared to other contexts. In contrast, race appears to influence opioid prescribing for chronic non-cancer pain and other contexts where opioid prescribing might be considered discretionary. ${ }^{25}$ Thus, the rationale for additional opioids in advanced cancer may have overridden physicians' hesitancy in prescribing based on race.

Second, we formulated our hypotheses on data on pain prescribing in general, ${ }^{25}$ but there are sparse data regarding disparities in pain management in advanced cancer. Before our study, only one small study suggested an absence of racial disparities in pain prescribing for patients with advanced

Table 5 Oncologist and PCP Opioid Prescription vs. No Opioid Prescription by Standardized Patient Race, Activation and Physician Characteristics (Mixed Model Logistic Regression)

\begin{tabular}{|c|c|c|c|c|c|c|}
\hline \multirow[b]{3}{*}{ Black SP } & \multicolumn{3}{|c|}{$\begin{array}{l}\text { Oncologists only } \\
\text { ( } n=45 \text { ONC/81 visits) }\end{array}$} & \multicolumn{3}{|c|}{$\begin{array}{l}\text { Primary care only } \\
(n=51 \text { PCPs/98 } \\
\text { visits })\end{array}$} \\
\hline & \multirow{2}{*}{$\frac{\mathbf{O R}}{0.24 *}$} & \multicolumn{2}{|c|}{$95 \% \mathrm{CI}$} & \multirow{2}{*}{$\frac{\text { OR }}{1.04}$} & \multicolumn{2}{|c|}{$95 \% \mathrm{CI}$} \\
\hline & & 0.07 & 0.81 & & 0.12 & 9.16 \\
\hline Activated SP & 3.96 & 1.24 & 12.69 & 0.72 & 0.19 & 2.69 \\
\hline Site & $0.28 *$ & 0.07 & 1.12 & $0.09 *$ & 0.01 & 1.14 \\
\hline Female physician & 1.05 & 0.29 & 3.88 & 0.58 & 0.06 & 6.09 \\
\hline $\begin{array}{l}\text { Physician age } \\
\text { (years) } \\
\text { Physician race }\end{array}$ & 1.01 & 0.95 & 1.06 & 0.95 & 0.87 & 1.04 \\
\hline Black & 0.45 & 0.11 & 1.79 & 0.85 & 0.06 & 12.63 \\
\hline Asian & 2.36 & 0.32 & 17.36 & 0.40 & 0.02 & 8.62 \\
\hline Fixed intercept & 6.16 & 0.30 & 125.37 & & & \\
\hline \multirow[t]{2}{*}{378.34} & 0.65 & \# & & & & \\
\hline & $\sigma^{2}$ & \multicolumn{2}{|c|}{$95 \% \mathrm{CI}$} & $\sigma^{2}$ & \multicolumn{2}{|c|}{$95 \% \mathrm{CI}$} \\
\hline Random intercept & 0.01 & 0.00 & $\#$ & 2.87 & 1.37 & 6.04 \\
\hline
\end{tabular}

$S P$, standardized patient; OR, odds ratio; $C I$, confidence interval $* p<0.05$

\# Very large number

$\sim$ Referent $=$ white cancer. ${ }^{26}$ More recently, one study reported no disparities in opioid prescribing in advanced breast cancer. ${ }^{27}$ In contrast, three recent observational studies have reported disparities in cancer pain management at varying stages, but all have important limitations. Fisch et al. ${ }^{5}$ reported significant racial disparities in pain management, yet their sample included early and advanced disease; like us, they did not examine within-physician prescribing differences. Bernabei et al. reported that minority nursing home patients with cancer were less likely to receive any analgesic medication, but they grouped all minorities together. ${ }^{28}$ Hunnicutt et al. reported more uncontrolled pain among black and other minority nursing home residents with cancer $^{29}$ yet did not distinguish by stage of cancer. Thus, our field experimental research provides important clarification of the ambiguous findings from these observational data.

Third, study limitations might have contributed to largely negative findings. Strengths of our study include using an adequately powered randomized field experiment design, high SP role fidelity, and low detection rate. As with all SP studies, actual patients may differ from the SP roles in ways that we did not approximate. It is possible that the SP role itself may have inadvertently reduced racial differences and prescribing in general. Our SPs presented as having been prescribed an opioid; physician decision-making may differ depending on whether patients requested new opioid prescriptions, the continuation of existing doses or a dose increase. It is also possible that, by controlling for activation between SPs of different races, we may have eliminated naturally occurring differences among real black and white patients with cancer, such as relative reluctance of black patients to present their concerns or ask questions. ${ }^{11}$ Furthermore, the contribution of race and socioeconomic status (SES) to disparities is complex; ${ }^{30}$ disparities may be partially attributable to the interactive effect of race and SES. Markers of low SES $^{31}$ may activate implicit biases, particularly toward black people. ${ }^{32}$ Thus, giving our SPs identical education, 
family, and work histories may have attenuated disparities that might have been observed in actual patients.

While our study failed to confirm hypothesized effects, post hoc analyses suggest disparities in prescribing opioids by specialty. We observed that oncologists (but not PCPs) prescribed no opioid at all to a larger percentage of black than white SPs. This exploratory finding suggests that combining data across specialties may have masked race effects. It is possible that this unexpected difference between PCPs and oncologists reflects that while oncologists were more likely, in general, to prescribe higher doses than PCPs, it appears that their prescribing was affected by race. While oncologists prescribed more pain medicine overall than PCPs in our study, observational studies have found that oncologists prescribe fewer adequate dosages to minorities. ${ }^{5,} 33$ This finding suggests caution in concluding that there are no racial disparities in opioid prescribing in advanced cancer.

Finally, we noted that only $71 \%$ of physicians prescribed any opioid to a patient with advanced cancer and uncontrolled pain, and only $38 \%$ of physicians prescribed an adequate dosage according to current guidelines. Physicians may have lacked knowledge about opioid prescribing or they may have wished to defer prescribing until they had a chance to review a new patient's medical records more carefully. Because of increasing concern about the opioid epidemic, ${ }^{34}$ physicians may have become more reluctant to prescribe as the study progressed.

Additional potential study limitations include that participating physicians might differ from those who did not, limiting generalizability to PCPs or oncologists, that participating physicians may have had more interest in research and in communication compared to non-participants and that our results are limited to male cancer patients and should not be extrapolated to women. ${ }^{35,36}$ While we considered Hawthorne effects, given the minimal contact we had with each individual physician, Hawthorne effects would be an unlikely explanation for our findings.

\section{CONCLUSION}

We found that patient race did not affect physicians' prescribing patterns in general when faced with a male patient with stage IV lung cancer patients who had been receiving inadequate doses of opioids for painful bone metastases, nor did race affect pain assessment. Patient activation was associated with improved pain assessment but did not modify the effect of race on prescribing or on pain assessment. Post hoc findings that oncologists were less likely to prescribe opioids to black patients and the factors that lead to suboptimal opioid prescribing by most of our participating physicians in advanced cancer should be explored in future studies.

Grant Support: The National Cancer Institute (NCI) supported this project: 1R01CA155376. Results from our study have not been published or presented before this submission. The study was conducted through the investigators' institutions: Purdue University, the University of Rochester, and the University of Michigan.

Corresponding Author: Ronald M. Epstein, MD; Family Medicine Research Programs University of Rochester, Rochester, NY, USA (e-mail: ronald_epstein@urmc.rochester.edu).

Author Contributions All authors listed have contributed sufficiently to the project to be included as authors, and all those who are qualified to be authors are listed in the author byline.

\section{Compliance with Ethical Standards:}

Conflict of Interest: The authors declare that they do not have a conflict of interest.

Publisher's note Springer Nature remains neutral with regard to jurisdictional claims in published maps and institutional affiliations.

\section{REFERENCES}

1. Institute of Medicine. How Far Have We Come in Reducing Health Disparities? Progress since 2000 (Workshop Summary). Washington, DC: The National Academies Press; 2012.

2. U.S. Department of Health. HHS Action Plan to Reduce Racial and Ethnic Health Disparities Implementation Progress Report. Washington, D.C. HHS; 2015: 1-38.

3. Martinez KA, Snyder CF, Malin JL, Dy SM. Is race/ethnicity related to the presence or severity of pain in colorectal and lung cancer? J Pain Symptom Manag. 2014;48(6):1050-1059. https://doi.org/10.1016/j. jpainsymman.2014.02.005.

4. Green CR, Hart-Johnson T, Loeffler DR. Cancer-related chronic pain: examining quality of life in diverse cancer survivors. Cancer. 2011;117(9):1994-2003. https://doi.org/10.1002/cncr.25761.

5. Fisch MJ, Lee J-W, Weiss $\mathbf{M}$, et al. Prospective, observational study of pain and analgesic prescribing in medical oncology outpatients with breast, colorectal, lung, or prostate cancer. JCO. 2012;30(16):19801988. https://doi.org/10.1200/JCO.2011.39.2381.

6. Meghani SH, Thompson AML, Chittams J, Bruner DW, Riegel B. Adherence to analgesics for cancer pain: a comparative study of African Americans and Whites using an electronic monitoring device. J Pain. https://doi.org/10.1016/j.jpain.2015.05.009.

7. Stein KD, Alcaraz KI, Kamson C, Fallon EA, Smith TG. Sociodemographic inequalities in barriers to cancer pain management: a report from the American Cancer Society's Study of Cancer Survivors-II (SCS-II). Psycho-Oncology. 2016;25(10):1212-1221. https://doi.org/10. 1002/pon.4218.

8. Anderson KO, Mendoza TR, Valero V, et al. Minority cancer patients and their providers. Cancer. 2000;88(8):1929-1938. https://doi.org/10. 1002/(SICI) 1097-0142(20000415)88:8<1929::AID-CNCR23>3.0.CO;2-2.

9. Bonham VL. Race, ethnicity, and pain treatment: Striving to understand the causes and solutions to the disparities in pain treatment. J Law Med Ethics. 2001;28:52-68.

10. Hoffman KM, Trawalter S, Axt JR, Oliver MN. Racial bias in pain assessment and treatment recommendations, and false beliefs about biological differences between blacks and whites. PNAS. 2016;113(16):4296-4301. https://doi.org/10.1073/pnas. 1516047113.

11. Gordon HS, Street RL, Sharf BF, Souchek J. Racial differences in doctors' information-giving and patients' participation. Cancer. 2006;107(6):1313-1320.

12. Hibbard JH, Greene J. What the evidence shows about patient activation: better health outcomes and care experiences; fewer data on costs. Health Aff. 2013;32(2):207-214. https://doi.org/10.1377/hlthaff. 2012.1061.

13. Street RL, Tancredi DJ, Slee C, et al. A pathway linking patient participation in cancer consultations to pain control. Psycho-Oncology. 2014;23(10):1111-1117. https://doi.org/10.1002/pon.3518.

14. Mishel MH, Germino BB, Lin L, et al. Managing uncertainty about treatment decision making in early stage prostate cancer: a randomized clinical trial. Patient Educ Couns. 2009;77(3):349-359. https://doi.org/ 10.1016/j.pec.2009.09.009.

15. Siminoff LA, Graham GC, Gordon NH. Cancer communication patterns and the influence of patient characteristics: disparities in information- 
giving and affective behaviors. Patient Educ Couns. 2006;62(3):355-360. https://doi.org/10.1016/j.pec.2006.06.011.

16. Elias CM, Shields CG, Griggs JJ, et al. The social and behavioral influences (SBI) study: study design and rationale for studying the effects of race and activation on cancer pain management. BMC Cancer. 2017;17(1):1-11. https://doi.org/10.1186/s12885-017-3564-2.

17. Hibbard JH, Stockard J, Mahoney ER, Tusler M. Development of the Patient Activation Measure (PAM): conceptualizing and measuring activation in patients and consumers. Health Serv Res. 2004;39(4 Pt 1):1005-1026.

18. Kaplan SH, Greenfield S, Gandek B, Rogers WH, Ware JE Jr. Characteristics of physicians with participatory decision-making styles. Ann Intern Med. 1996;124(5):497-504.

19. Equianalgesic Table for Adults. 2017. http://www. compassionandsupport.org/pdfs/professionals/pain/equi_table_(EX). pdf. Accessed October 19, 2018.

20. Shields CG, Finley MA, Elias CM, et al. Pain assessment: the roles of physician certainty and curiosity. Health Commun. 2013;28(7):740-746. https://doi.org/10.1080/10410236.2012.715380.

21. Davis MP, Dala S, McPherson ML, Sloan PA, Goforth H, Roeland E. Essentials 3: pain assessment and management. Available from the: American Academy of Hospice and Palliative Medicine; 2017. http:// aahpm.org/self-study/hpm-pass.

22. Snijders TAB. Power and sample size in multilevel linear models. In: Everette BS, Howell DC, eds. Encyclopedia of statistics in behavioral science. Vol 3. Chichester: John Wiley \& Sons, Ltd; 2005:1570-1573. https://doi.org/10.1002/0470013192.bsa492.

23. American Society of Clinical Oncology. Facts \& Figures: Diversity in Oncology. ASCO. https://www.asco.org/practice-guidelines/cancercare-initiatives/diversity-oncology-initiative/facts-figures-diversity. Published January 29, 2016. Accessed October 19, 2018.

24. Stout E, Sexton P, Meghani SH. Racial differences in adherence to prescribed analgesia in cancer patients: an integrated review of quantitative research. J Clin Outcomes Manag. 2017;24(1). https://www. mdedge.com/jcomjournal/article/145953/pain/racial-differences-adherence-prescribed-analgesia-cancer-patients. Accessed October 19, 2018.

25. Meghani SH, Byun E, Gallagher RM. Time to take stock: a metaanalysis and systematic review of analgesic treatment disparities for pain in the united states. Pain Med. 2012;13(2):150-174. https://doi.org/10. 1111/j.1526-4637.2011.01310.x.

26. Rolnick SJ, Jackson J, Nelson WW, et al. Pain management in the last six months of life among women who died of ovarian cancer. J Pain
Symptom Manag. 2007;33(1):24-31. https://doi.org/10.1016/j. jpainsymman.2006.06.010

27. Check DK, Samuel CA, Rosenstein DL, Dusetzina SB. Investigation of racial disparities in early supportive medication use and end-of-life care among medicare beneficiaries with stage IV breast cancer. JCO. 2016;34(19):2265-2270. https://doi.org/10.1200/JCO.2015.64.8162.

28. Bernabei R, Gambassi G, Lapane $\mathbf{K}$, et al. Management of pain in elderly patients with cancer. JAMA. 1998;279(23):1877-1882.

29. Hunnicutt JN, Ulbricht CM, Tjia J, Lapane KL. Pain and pharmacologic pain management in long-stay nursing home residents. Pain. 2017;158(6):1091-1099. https://doi.org/10.1097/j.pain. 0000000000000887 .

30. Williams DR, Mohammed SA, Leavell J, Collins C. Race, socioeconomic status and health: complexities, ongoing challenges and research opportunities. Ann N Y Acad Sci. 2010;1186:69-101. https://doi.org/ 10.1111/j.1749-6632.2009.05339.x.

31. Crimmins EM, Hayward MD, Seeman Teresa E. Race/ethnicity, socioeconomic status, and health. In: Anderson NB, Bulatao RA, Cohen B, National Research Council (US) Panel on Race E, eds. Critical perspectives on racial and ethnic differences in health in late life. Washington, D.C.: National Academies Press (US); 2004.

32. Burgess DJ, van Ryn M, Crowley-Matoka M, Malat J. Understanding the provider contribution to race/ethnicity disparities in pain treatment: insights from dual process models of stereotyping. Pain Med. 2006;7(2):119-134. https://doi.org/10.1111/j.1526-4637.2006.00105.

33. Mack DS, Hunnicutt JN, Jesdale BM, Lapane KL. Non-Hispanic BlackWhite disparities in pain and pain management among newly admitted nursing home residents with cancer. J Pain Res. 2018;11:753-761. https://doi.org/10.2147/JPR.S158128.

34. Koyyalagunta D, Bruera E, Aigner C, Nusrat H, Driver L, Novy D. Risk stratification of opioid misuse among patients with cancer pain using the SOAPP-SF. Pain Med. 2013;14(5):667-675. https://doi.org/10.1111/ pme. 12100 .

35. Payne R, Medina E, Hampton JW. Quality of life concerns in patients with breast cancer. Cancer. 97(1):311-317. https://doi.org/10.1002/ cncr. 11017.

36. Vicini F, Jones P, Rivers A, et al. Differences in disease presentation, management techniques, treatment outcome, and toxicities in AfricanAmerican women with early stage breast cancer treated with breastconserving therapy. Cancer. 116(14):3485-3492. https://doi.org/10. $1002 /$ cncr.25088. 